\title{
Fetal Ventriculomegaly and Outcomes: About 3 Cases
}

\author{
Mama Sy Diallo1*, Henriette Poaty², Simon Azonbankin³, Oumar Faye'1, Flore Gangbo ${ }^{3}$ \\ ${ }^{1}$ Histology-Embryology and Cytogenetics Laboratory, Faculty of Medicine, Cheikh Anta Diop University, Dakar, Senegal \\ ${ }^{2}$ Histology-Embryology and Genetics Unit, Faculty of Health Sciences, Marien Ngouabi University, Brazaville, Congo \\ ${ }^{3}$ Histology-Embryology and Cytogenetics Unit, Faculty of Health Sciences, Abomey-Calavi University, Cotonou, Benin \\ Email: *mamatasy@yahoo.fr
}

How to cite this paper: Diallo, M.S., Poaty, H., Azonbankin, S., Faye, O. and Gangbo, F. (2019) Fetal Ventriculomegaly and Outcomes: About 3 Cases. Open Journal of Pathology, 9, 41-49.

https://doi.org/10.4236/ojpathology.2019.9 $\underline{3005}$

Received: April 28, 2019

Accepted: July 5, 2019

Published: July 8, 2019

Copyright $\odot 2019$ by author(s) and Scientific Research Publishing Inc. This work is licensed under the Creative Commons Attribution International License (CC BY 4.0).

http://creativecommons.org/licenses/by/4.0/

(c) (i) Open Access

\begin{abstract}
Introduction: Ventriculomegaly is one of the most common abnormalities detected by prenatal ultrasound. This entity can be associated with brain abnormalities and other malformations. In order to perform a good prenatal counseling, the diagnosis is essential. Objective: Our purpose was to report the management of 3 cases of ventriculomegaly in our practice and underline the benefits of the neuropathologic exam. Methods: We analyzed retrospectively 3 medical files concerning fetus that were diagnosed as having one or two ventricles of $>10 \mathrm{~mm}$ and a follow up for prenatal diagnosis. Results: All cases were diagnosed between 22 and 27 weeks of gestation by an ultrasound. In a case, the ventriculomegaly evolved rapidly to a hydrocephalus. In two cases, the pregnancy was terminated with medical interruption by the parent's request. Amniocentesis confirmed the diagnosis of congenital toxoplasmosis in case 2 there were no chromosomal abnormalities after karyotyping. Causes included holoprosencephaly, congenital toxoplasmosis and mesencephalosynapsis. Conclusion: Ultrasonography may detect ventriculomegaly nerverthless in the cases presented, pathology exam was essential to assess the diagnostic. Causes are numerous and prognosis variable. We recommand MRI that is more and more accessible in our regions in the follow up of this entity and neuropathology exam in case of termination of the pregnancy. The establishment of main causes of ventriculomegaly in our regions (infectious causes for example) could help to prevent this outcome in our practice.
\end{abstract}

\section{Keywords}

Fetal Ventriculomegaly, Neuropathology, Prenatal Diagnosis

\section{Introduction}

Fetal Ventriculomegaly (FVM) is defined as an enlargement of the lateral cere- 
bral ventricles of the fetus. It can be a variation of the normal or the sign of an underlying pathology. The generic term ventriculomegaly has been preferred to ventricular dilatation and/or hydrocephalus, which already presupposes a pathophysiological mechanism [1].

It is defined in ultrasonographic imaging by a threshold value that is $10 \mathrm{~mm}>$ +4 DS in an axial plane and in a standardized measurement meeting strict anatomical criteria [2] [3]. The presence of ventriculomegaly at the Ultrasonography is one of the first signs of call to the discovery of a cerebral malformation in prenatal diagnosis. It can evolve to a hydrocephalus with increasement of the volume of cerebrospinal fluid (CSF) and be responsible for high intracranial pressure [1] [4].

Ventriculomegaly can be the result of very different mechanisms. The cause can be from a genetic origin and other etiological factors such as infections, toxic or nutritional deficiencies may be involved [5].

The determination of the cause is important to be able to establish a counsel and to ensure an effective prevention if the cause is of environmental origin, toxic, infectious, defective or genetic. Foeto-pathological examination, in particular neuropathological examination, is essential in this etiological approach.

The purpose of our work is to report through 3 observations of fetus with ventriculomegaly, the contribution of the etiological approach and the feto-pathological examination in the determination of mechanisms and etiological factors involved.

\section{Methods}

We conducted a retrospective analysis of the fetal records of medical termination of pregnancy or fetal death in utero at 2 centers that are the Histology-Embryology and Cytogenetics laboratory of the Faculty of Medicine of Dakar (Senegal) and the Histology-Embryology and Cytogenetics unit of the Faculty of Health Sciences of Cotonou (Benin) between 2006 and 2018.

The study material was filed from fetus with fetal abnormalities detected by ultrasound and referred for suspiscion of brain abnormalities in the prenatal medicine unit called "Pathologic pregnancy" and then in the fetopathologic unit. The diagnosis of VM was retained when ultrasound measurement of the ventricular junction was greater than $10 \mathrm{~mm}$. This measurement was performed on an axial section passing just above the plane of the thalamus by placing the "calipers" perpendicularly to the major axis of the ventricle, from the lateral wall to the medial wall of the ventricle lumen, immediately behind the choroid plexuses [3].

So the study material concerned 10 files. We included all files (3 fetuses) with a complete investigation in which ventriculomegaly was diagnosed with or without other brain abnormalities during a second or third trimester ultrasound with assessment for an etiology. Namely, we collected data from: 1) an medical history in search of toxins and eating habits, 2) an ultrasound, 3) "TORCH" se- 
rologies for toxoplasmosis, mumps, rubella, CMV and Herpes simplex virus and syphilis. 4) an amniocentesis and a karyotype. 5) the signed forms of informed consent from parents concerning investigation like karyotyping and pathology.

Indeed autopsy was performed only when allowed by parents with signed forms. The pathologic and the neuropathological examination were done following a protocol of good practice. We excluded files, without "TORCH" serologies or amniocentesis. Our study got the approval of the ethics committee of the doctoral school of human biology from the medical school of Cheikh anta Diop University of Dakar.

\section{Observations}

The fetuses examined are from patients who have had a medical abortion (cases 1 and 3). In case 2, the fetus was examined after expulsion following a fetal death in utero at 26 weeks of pregnancy. We report the results of the ultrasound in Figure 1. The data of the autopsy were summarized in Table 1 . The neuroanatomical lesions and the histologic findings are reported respectively in Figure 2 and Figure 3.

The results of the post mortem examination of fetuses 1 and 3 are reported in Table 1.

\section{Case 1}

Mrs. L.M. 28 years old is a primigravida. She was diagnosed as having a fetus with ventriculomegaly at 25 weeks of gestation (Figure 1(a)) that evolved rapidly to a hydrocephalus in the same week. Termination of the pregnancy was performed at 26 weeks of gestation. "TORCH" serologies were negative and amniocentesis helped
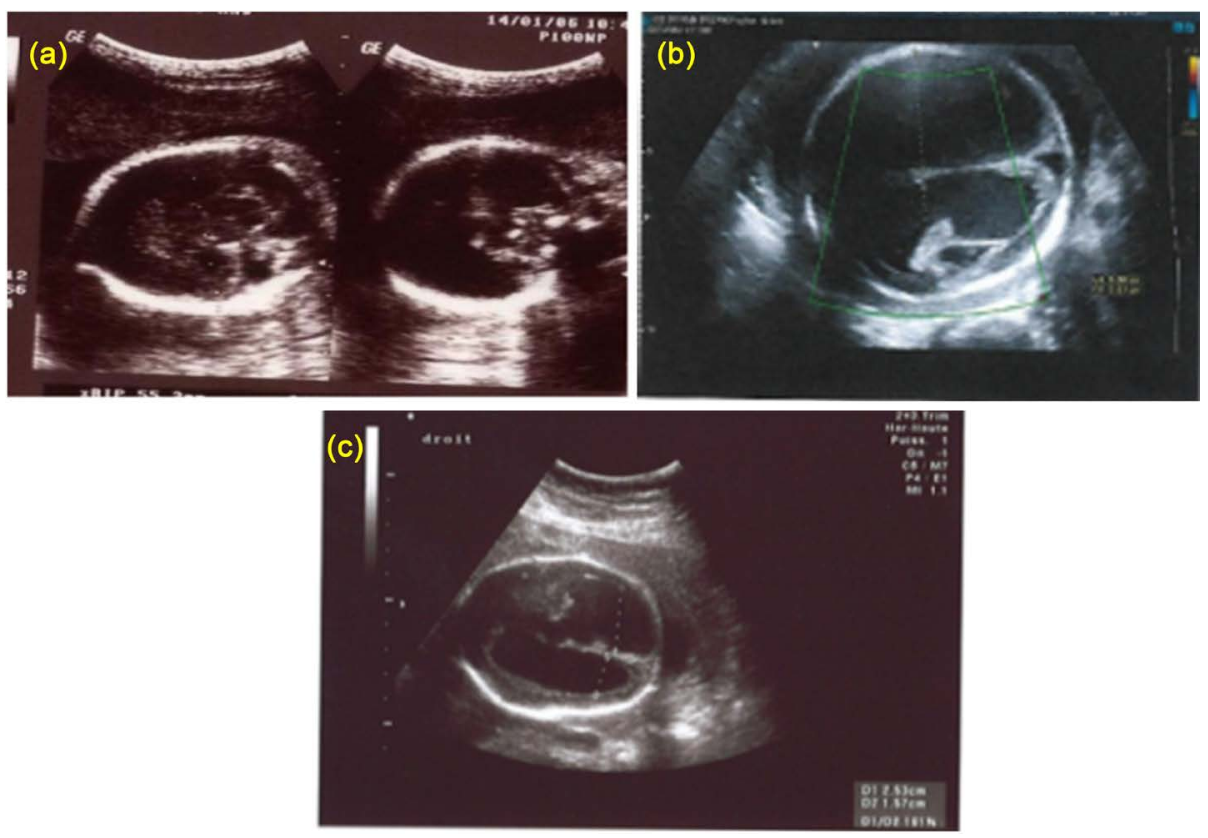

Figure 1. Ultrasonography results. (a) Ventriculomegaly with absence of medial structures (alobar holoprosencephaly, Case 1); (b) bilateral ventriculomegaly and incomplete septum (Case 2); (c) bilateral ventriculomegaly and septal disruption (Case 3). 

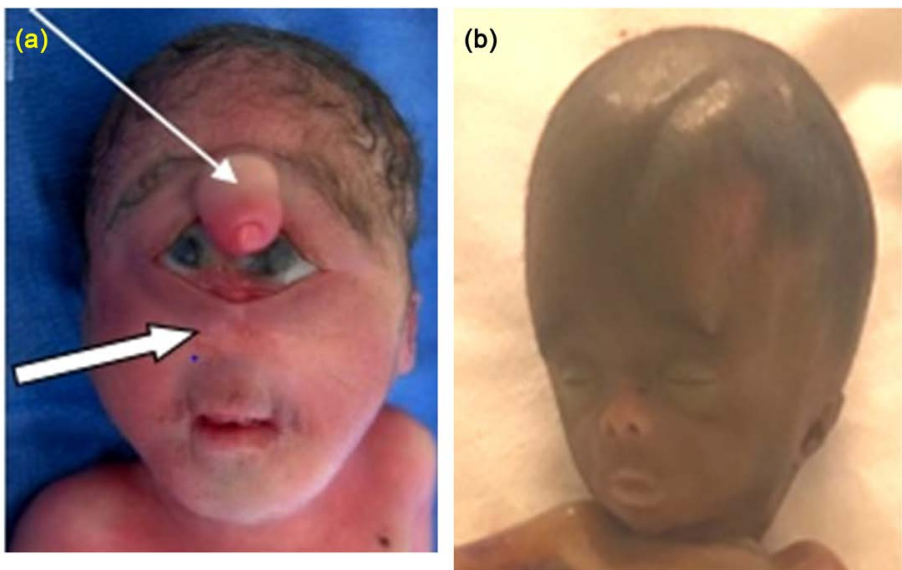

Figure 2. Morphology of the skull and the face. (a) cyclopia, proboscis, arhinia and long philtrum (case 1), (b) macrocrania, bulging fontanelles (case 2).
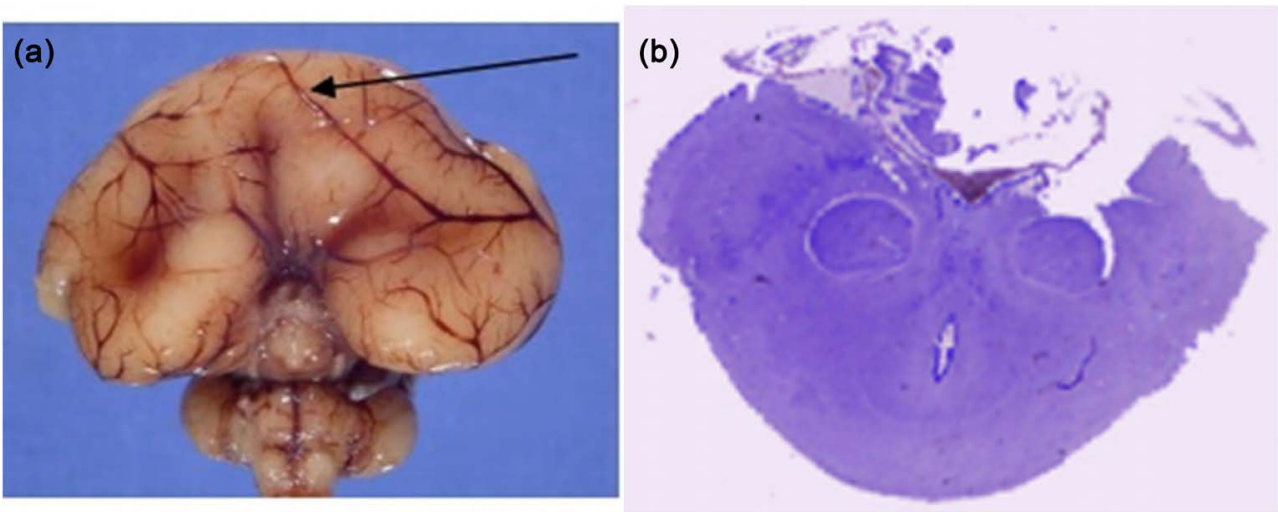

Figure 3. Fetopathological examination: (a) macroscopical examination: alobar holoprosencephaly with absence of interhemispheric fissure (Case 1). (b) microscopical examination: mesencephalosynapsis with "dome" aspect of the mesencephalon with no differentiation of the inferior colliculi. Stenosis of the Sylvius aqueduct with a reduced caliber (observation after cresyl violet staining and $\times 100$ magnification).

Table 1. Results of post mortem exam.

\begin{tabular}{|c|c|c|c|}
\hline Foetus & External Exam & Macroscopy & Microscopy \\
\hline 1 & $\begin{array}{l}\text { Proboscis }(1.5 \mathrm{~cm}) \\
\text { arrhinia, } \\
\text { philtrum long, } \\
\text { Cleft palate }(2.5 \mathrm{~cm})\end{array}$ & $\begin{array}{l}\text { Brain with absence of interhemispheric } \\
\text { fissure } \\
\text { Absence of bulb and olfactory tract } \\
\text { Normal cerebellum. } \\
\text { Heart abnormalities with right heart tip, } \\
\text { atrio-ventricular communication }\end{array}$ & No available data \\
\hline 3 & $\begin{array}{l}\text { macrocephaly, } \\
\text { bulging } \\
\text { fontanelle }\end{array}$ & $\begin{array}{l}\text { Brain with triventricular dilation, } \\
\text { septum disruption, corpus callosum } \\
\text { present but broken } \\
\text { Brainstem: Poorly individualized } \\
\text { colliculi, reduced aqueduct of sylvius } \\
\text { Cerebellum with a transverse diameter } \\
\text { at } 18 \mathrm{~mm} \text { (for a normal size at } 27 \mathrm{~mm} \text { at } \\
\text { this stage of development) with normal } \\
\text { morphology }\end{array}$ & $\begin{array}{l}\text { Brainstem: weakly } \\
\text { differentiated inferior } \\
\text { colliculi, reduced aqueduct } \\
\text { of Sylvius in favour of } \\
\text { mesencephalosynapsis }\end{array}$ \\
\hline
\end{tabular}


to establish a normal karyotype of the fetus with formula 46, XX. Alobar holoprosencephaly was diagnosed at the post morten examination. The fetus had facial anomalies, with cyclopia, proboscis, arhinia, long philtum, and a $2.5 \mathrm{~cm}$ cleft palate (Figure 2(a)).

\section{Case 2}

Mrs. A.M. 21 years old is also primigravida. The analysis of the obstetrical file reveals a toxoplasmic seroconversion during the pregnancy. Indeed, reading his first prenatal report at 7 weeks of amenorrhea, revealed a serology for low positive IgM toxoplasmosis with negative IgG without subsequent control. A TORCH serological assessment was performed after the discovery of ventriculomegaly at 22 weeks (Figure 1(b)) and demonstrated the positivity of IgM and IgG antibodies for toxoplasmosis. The brain calcifications found on the ultrasound were in favor of the diagnosis Amniocentesis was performed for a cytogenetic sample and a parasite search by RT-PCR (real-time polymerase chain reaction). The karyotype formula was $46, \mathrm{XX}$. Fetal toxoplasmic infection was confirmed by RT-PCR. Fetal death in utero occurred at 26 weeks of gestation. After expulsion, the parents refused the autopsy but allowed a morphological examination of the fetus. A complete external morphological examination and biometric measurements were performed in agreement with the parents who refused the autopsy. Morphological examination revealed macrocranium, bulging fontanelles and hypertelorism. The cranial perimeter was at the $90^{\text {th }}$ percentile compared to the fetus of the same term (Figure 2(b)).

\section{Case 3}

The anamnesis of Madame A.T. 26 years old, also primigravida highlights a notion of insulin-dependent diabetes in the family, without any other particular antecedents. She underwent medical abortion at 27 weeks of gestation for which the indication was bilateral ventriculomegaly (Figure 1(c)). "TORCH" serologies were negative and the karyotype was normal with the formula 46, XX. The fetus presented macrocephaly and bulging fontanelle. Mesencephalosynapsis was diagnosed after neuropathologic examination.

\section{Discussion}

\section{Prevalence}

Brain malformations account for $9 \%$ of isolated malformations and $16 \%$ of polymalformative syndromes, so for a quarter of all fetal malformations [7]. Fetal brain ventriculomegaly (FVM) is the most common fetal brain abnormality seen on ultrasound [8]. This observation remains the same in our regions, as described in Senegal [9] or in Benin [4] with detection during the ultrasound examination of the second or the third trimester. It is nevertheless only a sign of ultrasound call, witnessing fetal brain pathology. It leads to both invasive procedures (amniocentesis) and anxiety for the couple [1]. The detection of FVM often spells poor prognosis especially if there are associated malformations. Den Hollander [10] indicates that the prognosis seems better with isolated ventricu- 
lomegaly. It is therefore necessary to establish a precise diagnosis in order to determine the prognosis for the fetus and perform prenatal counseling for prevention [11]. The causes are multiple and can be from infectious, vascular or toxic origin or still remain unknown [8].

In our study, the fotopathological examination established the diagnosis of alobar holoprosencephaly and mesencephalosynapsis. Chromosomal abnormalities are classically reported in minor ventriculomegaly (up to 27\%) [12]. In our study, karyotypes were normal.

In case of toxoplasmosis, the parasite destroys the cerebral parenchyma with foci of necrosis [13]. The destruction of the choroid plexuses and parenchyma can be responsible for CSF resorption disorder. Cyst formation is also an obstacle to its flow [14]. If the autopsy was performed in the case of the fetus with toxoplasmosis, it would have detected ophthalmological lesions like chorioretinitis, microphthalmia, cataract or glaucoma, especially in case of severe infestation [15].

Holoprosencephaly is a rare and serious malformation resulting from a lack of cleavage of the forebrain. During embryogenesis, primordial cerebral vesicles divide to give new vesicles [16] [17] with the exception of the mesencephalon (Figure 4).

The midbrain is initially a tubular structure with a wall composed of peri-ependymal grey substance and a peripheral white substance. The ependymal cavity originally very wide, will see its light decrease to form only a narrow channel, the aqueduct of mesencephalon or Sylvius, allowing the CSF to circulate from the $3^{\text {rd }}$ to the $4^{\text {th }}$ ventricle. On its dorsal surface, four reliefs will constitute the colliculi. The dorsal lips will proliferate and form the cerebellum.

Holoprosencephaly may be associated with facial abnormalities [4] [6]. It is characterized by the presence of a single ventricular cavity with or without interhemispheric septum. Thus, depending on the degree of septal agenesis, holoprosencephaly can be complete, alobar or semi-lobar [Hornoy, Dia].

Mesencephalosynapsis is defined as the fusion or absence of differentiation of

(a)

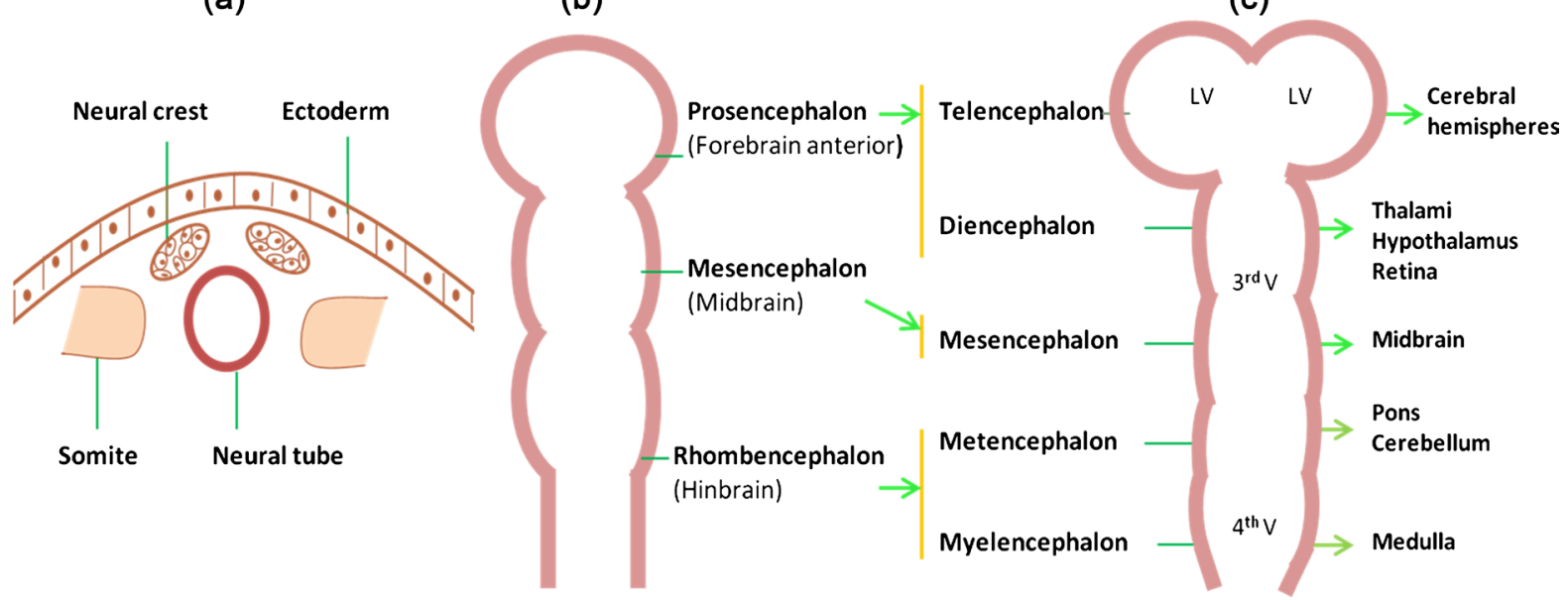

Figure 4. Neurulation and formation of the cerebral vesicles (a) neural tube at the end of the 3 WED, (b) primary cerebral vesicles at $4 \mathrm{WED}$, (c) secondary cerebral vesicles at the $5 \mathrm{WED}$. (Drawing according to Poaty [6]). 
the colliculi associated with a decrease in size of the Sylvius aqueduct diameter. In the case that we report, it is an isolated malformation. It is most often associated with other abnormalities including rhombencephalosynasis, with agenesis or hypogenesis of vermis, a fusion of dental nuclei and a fusion of the cerebellar lobes [18]. In other cases, mesencephalosynapsis may be associated with thalami and third ventricle fusion with diencephalon mesencephalosynapsis [19].

In Launay's study [8] concerning 61 fetuses followed for ventriculomegaly, these etiologies were found only once, respectively, with a case of semi-lobar holoprosencephaly, a case of stenosis of the Sylvius aqueduct and a case of cerebral toxoplasmosis. The final diagnosis was obtained after post-mortem examination and was established in about $40 \%$ of cases.

Some authors consider the mechanism of occurrence rather than etiology because the cause is sometimes difficult to establish. Indeed, a malformation responsible for the ventriculomegaly can be itself the result of a genetic, infectious or toxic etiology.

Thus, Darouich [5] describes 4 groups of pathologies that constitute $86 \%$ of disorders causing ventriculomegaly. These are in order of frequency: 1) malformations of the midline and the forebrain, including the stenosis of the Sylvius aqueduct, 2) cyto-architectural disorders of the brain with mainly neuronal ectopias, 3) hemorrhagic disorders, 4) CSF resorption or destruction of brain tissue.

In Darouich series [5], only $21 \%$ of 183 fetuses were able to have a substantiated diagnosis. Studies comparing the results of imaging and pathological examination indicate that even if the overall correlation is good, anatomic pathology can be used to correct the diagnosis [20]. In Launay study [8], the pathological examination revealed microscopic foci of neuronal heterotopy of the cerebellum and other diagnoses that had not been identified on MRI, such as stenosis of the cerebral Sylvius aqueduct, but also anoxo-ischemic lesions or the presence of a rhombencephalosynapsis. Thus, the foetopathological examination reveals unknown malformations allowing the establishment of a strategy for subsequent pregnancies.

In Ferguson study [21], the neuropathological study was able to demonstrate an active proliferation of the parasite in the fetal brain despite the appearance of an immune response with positive IgG and suggest continued treatment of toxoplasmosis in pregnant women even after seroconversion.

The neuropathological study is a valuable tool to assess an etiology in case of venticulomegaly when it is possible. It is an essential morphological contribution in order to classify malformations in nosological groups such as mild line abnormalities. If pathological entities can be identified by their mechanism of occurrence, the etiology in question is not always identified. Thus, diagnosis at the molecular level remains a research topic to explore [5].

\section{Conclusion}

Fetal Ventriculomegaly is one of the most common signs for fetal brain disease 
in prenatal diagnosis. MRI, now more accessible in our regions, is to propose to better guide a justified termination of pregnancy. A fetopathological examination is recommended to establish a precise diagnosis in case of termination of the pregnancy. This approach in our practice would help, in order to establish the profile of main causes in our regions and be able to perform adequate prenatal counseling.

\section{Acknowledgements}

The authors sincerely acknowledge the obstetricians who referred their cases and Patients and family for complying with us to realize this study.

\section{Conflicts of Interest}

The authors declare no conflicts of interest regarding the publication of this paper.

\section{References}

[1] Guibaud, L. (2009) Fetal Cerebral Ventricular Measurement and Ventriculomegaly: Time for Procedure Standardization. Ultrasound in Obstetrics \& Gynecology, 34, 127-130. https://doi.org/10.1002/uog.6456

[2] Pretorius, D.H., Drose, J.A. and Manco-johnson, M.L. (1986) Fetal Lateral Ventricular Ratio Determination during the Second Trimester. Journal of Ultrasound in Medicine, 5, 121-124. https://doi.org/10.7863/jum.1986.5.3.121

[3] Cardoza, J.D., Goldstein, R.B. and Filly, R.A. (1988) Exclusion of Fetal Ventriculomegaly with a Single Measurement: The Width of the Lateral Ventricular Atrium. Radiology, 169, 711-714. https://doi.org/10.1148/radiology.169.3.3055034

[4] Gangbo, F., Lokossou, A., Biaou, O., Lalèyè, A., Sossou, R., Carles, D., Alberti, E.M. and Darboux, R. (2006) About a Case of Alobar Holoprosencephaly Associated with a Probosis and an Atrioventricular Communication. Journal de la Socié té de Biologie Clinique, $\mathrm{N}^{\circ} 010,5-9$.

[5] Darouich, S., Boutaud, L., Bessières, B., Bonnière, M., Martinovic, J., Mechler, C., Alby, C., Bernard, J.P., Roth, P., Ville, Y., Malan, V., Vekemans, M., Attié-Bitach, T. and Encha-Razavi, F. (2017) Fetal Cerebral Ventricular Dilatation: Etiopathogenic Study of 130 Observations. Birth Defects Research, 109, 1586-1595. https://doi.org/10.1002/bdr2.1093

[6] Briard, M.L., Feingold, J., Bonaiti-Pellie, C., Lapeyre, F., Frézal, J. and Varangot, J. (1975) Frequency of Birth Defects. Archives Françaises de Pédiatrie, 32, 123-138.

[7] Poaty, H., Gentien, D., Reyes, C. and Silou, J. (2016) Macroscopic Analysis of Fetus Having Arhinencephaly, Synophtalmia and Holoprosencephaly. Human Genetics \& Embryology, 6, 135. https://doi.org/10.4172/2161-0436.1000135

[8] Launay, S., Cuilleret, V., Boyer, C., Mestdagh, P., Moisan, S., Vaast, P., Bourgeot, P., Denes, M., Rocourt, N. and Robert, Y. (2003) Magnetic Resonance Imaging Applications in obstetrics. Journal de Gynécologie Obstétrique et Biologie de la Reproduction (Paris), 32, 205-220.

[9] Dia, A.A., D’Almeida, F., Mbodji, M., et al. (2013) Case Report: Alobar Holoprosencephaly in a Context of Polymalformative Syndrome: Contribution of Imaging, about a Case. Pan African Medical Journal, 15, 83.

[10] Den Hollander, N.S., Vinkestijn, A., Schmitz-Van Plunder, P., Catsman-Berrevoets, 
C.E. and Wladimiroff, J.W. (1998) Prenatally Diagnosed Fetal Ventriculomegaly; Prognosis and Outcome. Prenatal Diagnosis, 18, 557-566. https://doi.org/10.1002/(SICI)1097-0223(199806)18:6<557::AID-PD303>3.3.CO;2V

[11] Valat, A.S., Dehouck, M.B., Dufour, P., et al. (1998) Fetal Ventriculomegaly. Etiology and Becoming, about 141 Observations. Journal de Gynécologie Obstétrique et Biologie de la Reproduction, 27, 782-789.

[12] Benacerraf, B.R. (2001) Unilateral Cerebral Ventriculomegaly. Is One Better than Two? Journal of Ultrasound in Medicine, 20, 179-181. https://doi.org/10.7863/jum.2001.20.3.179

[13] Body, G., Perrotin, F., Guichet, A., Paillet, C. and Descamps, P. (2001) The Practice of Prenatal Diagnosis. Éd Masson, Paris, 288-289.

[14] Cotty, F., Carpentier, M.A., Descamps, P., Perrotin, F. and Richard-Lenoble, D. (1997) Congenital Toxoplasmosis with Hydrocephalus: Prenatal Diagnosis and Developmental Outcome in a Treated Child. Archives de Pédiatrie, 4, 247-250. https://doi.org/10.1016/S0929-693X(97)87240-5

[15] Nizard, J. (2008) Toxoplasmosis and Pregnancy. Journal de Gynécologie Obstétrique et Biologie de la Reproduction, 37, F4-F9. https://doi.org/10.1016/S0368-2315(08)70497-6

[16] Hornoy, P., Mezzetta, L. and Adamsbaum, C. (2011) Prenatal Detection of Brain Anomalies with Ultrasonography. Journal of Radiology, 92, 111-117. https://doi.org/10.1016/j.jradio.2010.12.003

[17] Razavi, F. and Carles, D. (2008) Fetal and Placental Pathology Practice, Ouvrage Collectif de la société française de foetopathologie. Sauramps Médical, Maisons-Alfort, 163-169.

[18] Pasquier, L., Marcorelles, P., Loget, P., Pelluard, F., Carles, D., Perez, M.J., Bendavid, C., de La Rochebrochard, C., Ferry, M., David, V., Odent, S. and Laquerrière, A. (2009) Rhombencephalosynapsis and Related Anomalies: A Neuropathological Study of 40 Fetal Cases. Acta Neuropathologica, 117, 185-200.

https://doi.org/10.1007/s00401-008-0469-9

[19] Severino, M., Righini, A., Tortora, D., Pinelli, L., Parazzini, C., Morana, G., Accorsi, P., Capra, V., Paladini, D. and Rossi, A.M.R. (2017) Imaging Diagnosis of Diencephalic-Mesencephalic Junction Dysplasia in Fetuses with Developmental Ventriculomegaly. American Journal of Neuroradiology, 38, 1643-1646. https://doi.org/10.3174/ajnr.A5245

[20] Kehila, M., Halouani, A., Touhami, O., Abouda, H.S., Khlifi, A., Hmid, R.B., Benhassen, I., Masmoudi, A. and Chanoufi, M.B. (2016) Confrontation between Ultrasound and Fetopathological Examination Following Therapeutic Abortion Performed in a Maternity Clinic in Tunisia. Pan African Medical Journal, 25, 256. https://doi.org/10.11604/pamj.2016.25.256.10011

[21] Ferguson, D.J., Bowker, C., Jeffery, K.J., Chamberlain, P. and Squier, W. (2013) Congenital Toxoplasmosis: Continued Parasite Proliferation in the Fetal Brain Despite Maternal Immunological Control in Other Tissues. Clinical Infectious Diseases, 56, 204-208. https://doi.org/10.1093/cid/cis882 